\title{
HER2/neu and Ki-67 expression predict non-invasive recurrence following breast-conserving therapy for ductal carcinoma in situ
}

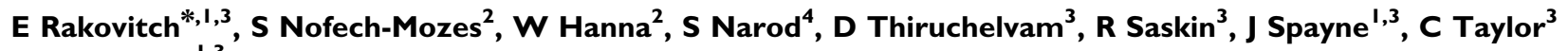 \\ and L Paszat ${ }^{1,3}$ \\ 'Department of Radiation Oncology, University of Toronto, Toronto, Canada; ${ }^{2}$ Department of Pathology, Sunnybrook Health Sciences Centre, University \\ of Toronto, 2075 Bayview Avenue, Toronto M4N 3M5, Canada; ${ }^{3}$ Institute of Clinical Evaluative Sciences, University of Toronto, Toronto, Canada; \\ ${ }^{4}$ Women's College Hospital Research Institute, University of Toronto, Toronto, Canada
}

BACKGROUND: Ductal carcinoma in situ (DCIS) is a non-invasive form of breast cancer that may progress to invasive cancer. Identification of factors that predict recurrence and distinguish DCIS from invasive recurrence would facilitate treatment recommendations. We examined the prognostic value of nine molecular markers on the risks of local recurrence (DCIS and invasive) among women treated with breast-conserving therapy.

METHODS: A total of 213 women who were treated with breast-conserving therapy between 1982 and 2000 were included; 141 received breast-conserving surgery alone and 72 cases received radiotherapy. We performed immunohistochemical staining on the DCIS specimen for nine markers: oestrogen receptor, progesterone receptor, Ki-67, p53, p2I, cyclinDI, HER2/neu, calgranulin and psoriasin. We performed univariable and multivariable survival analyses to identify markers associated with the recurrence. RESULTS: The rate of recurrence at 10 years was 36\% for patients treated with breast-conserving surgery alone and $18 \%$ for women who received breast-conserving surgery and radiotherapy. HER2/neu $+/$ Ki-67 + expression was associated with an increased risk of DCIS recurrence, independent of grade and age $(H R=3.22 ; 95 \% \mathrm{Cl}$ : 1.47-7.03; $P=0.003)$. None of the nine markers were predictive of invasive recurrence.

CONCLUSION: Women with a HER2/neu/neu + /Ki67 + DCIS have a higher risk of developing DCIS local recurrence after breast-conserving surgery.

British Journal of Cancer (2012) 106, I I60- | 165. doi: I0.1038/bjc.2012.4I www.bjcancer.com

Published online 23 February 2012

(C) 2012 Cancer Research UK

Keywords: DCIS; biomarkers; recurrence; breast-conserving surgery

Ductal carcinoma in situ (DCIS) is a non-invasive, highly treatable form of breast cancer. Ductal carcinoma in situ constitutes approximately $20 \%$ of breast cancers diagnosed through mammographic screening (Ernster et al, 2002). Following a diagnosis of DCIS, women are at elevated risk both for non-invasive (DCIS) recurrence and invasive local recurrence. Women who develop a local recurrence require additional treatment, such as further local excision or mastectomy, to reduce the risk of subsequent invasive breast cancer and potential breast cancer mortality (Solin et al, 1994; Silverstein et al, 1998).

Radiotherapy is highly effective in reducing the risk of local recurrence, but it requires a substantial time commitment from patients and carries potential side effects, including skin changes, cardiac morbidity and secondary malignancies (Fisher et al, 1998; Julien et al, 2000; Houghton et al, 2003; Paszat et al, 1998, 2007; Lauzier et al, 2011). At present, it is difficult to predict which women with DCIS will go on to develop recurrence following breast-conserving surgery for DCIS. Younger age at diagnosis and the presence of high-grade DCIS are associated with the development of local recurrence but these factors do not

*Correspondence: Dr E Rakovitch; E-mail: eileen.rakovitch@sunnybrook.ca Received 7 November 2011; revised 17 January 2012; accepted 19 January 2012; published online 23 February 2012 distinguish an individual's risk of developing DCIS from those at risk of invasive recurrence. As a result, most women diagnosed with DCIS receive radiotherapy following surgery.

In order to improve risk stratification and treatment recommendation for women with DCIS, there is a need to identify predictors of non-invasive local recurrence and invasive local recurrence following breast-conserving therapy. Several studies have evaluated the prognostic significance of biomarkers including oestrogen receptor (ER) expression, progesterone receptor (PR) expression and HER2/neu expression as predictors in DCIS but most of these studies were limited due to the number of patients included, variations in treatment and short follow-up (Ringberg et al, 2001; Provenzano et al, 2003; Cornfield et al, 2004). The largest study included a population-based cohort of women treated by breast-conserving surgery without radiotherapy. In this study, women with ER-/HER2/neu + /Ki67 + DCIS had a greater risk of developing DCIS recurrence than women with other expression profiles (Kerlikowske et al, 2010). However, only 33 cases in this study had this particular profile; therefore, we sought to validate their findings in our patient cohort. We evaluated the prognostic value of these markers and six additional biomarkers for the development of non-invasive (DCIS) and invasive breast cancer in women with DCIS treated by breastconserving therapy. 


\section{PATIENTS AND METHODS}

\section{Patients}

We reviewed the medical and pathology records of all 296 patients with a diagnosis of DCIS (alone or with microinvasion) who were treated at our institution between 1982 and 2000. Cases who were treated by mastectomy $(n=42)$ were excluded from the analysis because there were no local recurrences and our objective was to evaluate biomarkers of recurrence following breast-conserving therapy. There were 254 cases treated by breast-conserving therapy, including 172 cases treated by breast-conserving surgery alone $(n=172)$ and 82 cases treated by breast-conserving surgery followed by radiation. Tissue blocks were unavailable for 41 cases and these cases were excluded. Therefore, the study cohort includes 213 individuals, 141 cases treated by breast-conserving surgery alone and 72 cases treated by breast-conserving surgery and radiation. Data was obtained on age at diagnosis, clinical and pathological features and clinical outcomes, including the development of any local recurrence (DCIS or invasive), regional recurrence or distant recurrence. The presence of recurrent disease was validated by review of the pathology report. If the patient had not attended the cancer centre in the past 12 months, then followup information was obtained through correspondence with the primary physician and/or referring surgeon.

\section{Pathology}

For each case of DCIS, all diagnostic slides and blocks were reviewed by an expert breast pathologist, using standardised criteria. For non-palpable lesions, the entire specimen was submitted and serially sectioned at $0.5 \mathrm{~cm}$ intervals (average 30 blocks per case). Specimen radiographs were taken and foci of calcifications, areas of architectural distortion and resection margins were identified, sectioned and submitted for evaluation. For specimens with a grossly identifiable mass, sections were submitted to evaluate the distance between the tumour and the resection margins. Overall, we examined an average of 12 blocks per case. Tumour size was evaluated as a continuous variable $(\mathrm{cm})$. Nuclear grade was determined using the Holland classification (Holland et al, 1994) and categorised as low, intermediate and high. Lesions with mixed grade were coded as the highest grade observed. Comedo-necrosis was considered to be the presence of any architectural pattern of DCIS in which a central zone of necrotic debris with karyorrhexis was identified. Microinvasion was defined as the presence of invasive cancer measuring $\leqslant 1 \mathrm{~mm}$ (patients with an invasive component of greater size were considered to be invasive cancers and were excluded)(Edge et al, 2010). The resection margin status was reported as positive when DCIS was present at the inked or cauterised edge of the specimen and negative if there was no DCIS at the inked margin. For some patients, the surgical cavity was re-excised in order to obtain a negative margin. The final margin status refers to the resection margin of the final surgical specimen. The width of the negative resection margin represents the closest distance of DCIS to the edge of the specimen and was categorised as $\leqslant 3 \mathrm{~mm}, 4-9 \mathrm{~mm}$, $\geqslant 10 \mathrm{~mm}$ or unreported. Multifocality was defined as more than one distinct focus of DCIS, with at least $5 \mathrm{~mm}$ of intervening normal tissue (Sikand et al, 2005). For cases with multifocal DCIS, the size of the largest focus was recorded.

\section{Immunohistochemistry of molecular markers}

We evaluated the expression of ER, PR, HER2/neu, Ki67, p53, p21, cyclin D1, calgranulin and psoriasin on formalin-fixed paraffinembedded tissue sections, using immunohistochemistry (Table 1). A positive and negative control were included in every assay. The positive control for psoriasin and calgranulin consisted of two
Table I Characteristics of patients with DCIS in the study

\begin{tabular}{|c|c|c|c|}
\hline & $\begin{array}{l}\text { Breast- } \\
\text { conserving } \\
\text { surgery+ } \\
\text { radiotherapy } \\
(N=72)\end{array}$ & $\begin{array}{c}\text { Breast- } \\
\text { conserving } \\
\text { surgery } \\
(N=14 I)\end{array}$ & $P$-value \\
\hline Age mean (range) (years) & $54.4(33.4,81.6)$ & $58.1(27,86)$ & 0.04 \\
\hline \multicolumn{4}{|l|}{ Tumour size $(\mathrm{cm})$} \\
\hline Mean (range) & $1.2(0.09,5.0)$ & $0.8(0.02,2.5)$ & $<0.001$ \\
\hline \multicolumn{4}{|l|}{ Comedo necrosis } \\
\hline Yes & $48(67 \%)$ & 87 (62\%) & 0.48 \\
\hline No & $20(28 \%)$ & $53(37 \%)$ & \\
\hline Missing & $4(5 \%)$ & I (1\%) & \\
\hline \multicolumn{4}{|l|}{ Nuclear grade } \\
\hline Low & $5(7 \%)$ & $20(14 \%)$ & 0.034 \\
\hline Moderate & $27(38 \%)$ & $65(46 \%)$ & \\
\hline High & $38(53 \%)$ & $56(40 \%)$ & \\
\hline Missing & $2(2 \%)$ & & \\
\hline \multicolumn{4}{|l|}{ Multifocality } \\
\hline Yes & $33(46 \%)$ & $50(35 \%)$ & 0.14 \\
\hline No & $39(54 \%)$ & $91(65 \%$ & \\
\hline \multicolumn{4}{|l|}{ Microinvasion } \\
\hline Yes & $4(6 \%)$ & $4(3 \%)$ & 0.32 \\
\hline No & $68(94 \%)$ & $137(97 \%)$ & \\
\hline \multicolumn{4}{|l|}{ Size of negative margin (mm) } \\
\hline$\leqslant 3$ & $40(56 \%)$ & $78(61 \%)$ & 0.61 \\
\hline $4-9$ & $10(14 \%)$ & $22(17 \%)$ & \\
\hline$\geqslant 10$ & $19(27 \%)$ & $24(19 \%)$ & \\
\hline Missing & $2(3 \%)$ & $4(3 \%)$ & \\
\hline \multicolumn{4}{|l|}{ Molecular markers } \\
\hline HER2/neu+ & $19(26.4 \%)$ & $39(27.8 \%)$ & 0.84 \\
\hline Psoriasin continuous & $7.9(0,100)$ & $5.2(0,90)$ & 0.27 \\
\hline Psoriasin ( $\geqslant 10 \%)$ & $18(25.0 \%)$ & $20(14.2 \%)$ & 0.051 \\
\hline Calgranulin continuous & $5.2(0,75)$ & $11.1(0,100)$ & 0.06 \\
\hline Calgranulin $(\geqslant 10 \%)$ & $11(15.3 \%)$ & $31(22.0 \%)$ & 0.24 \\
\hline Ki67 continuos & $12.9(0,80)$ & $13.4(0,80)$ & 0.82 \\
\hline Ki67 $(\geqslant 10 \%)$ & $49(68.1 \%)$ & $91(64.5 \%)$ & 0.61 \\
\hline p53-continuous & $41.9(0,100)$ & $15.1(0,100)$ & $<0.001$ \\
\hline$p 53+(\geqslant 10 \%)$ & $44(61.1 \%)$ & $39(27.7 \%)$ & $<0.001$ \\
\hline ER positive & $59(81.9 \%)$ & $94(66.7 \%)$ & 0.02 \\
\hline PR positive & $52(72.2 \%)$ & 83 (58.9\%) & 0.06 \\
\hline Cyclin DI & $71.5(0,100)$ & $78.8(0,100)$ & 0.047 \\
\hline p21-continuous & $20.1(0,100)$ & $20.1(0,100)$ & 0.99 \\
\hline $\mathrm{p} 21+(\geqslant 10 \%)$ & $41(57.0 \%)$ & $74(52.4 \%)$ & 0.54 \\
\hline
\end{tabular}

cases of DCIS with an invasive component. In these cases positive psoriasin and calgranulin immunostains correlated with their gene upregulation as shown using DNA microarray technique (Seth et al, 2003). We used the MIB1 antibody for evaluating Ki67 expression. Nuclear staining was scored for ER, PR, Ki67, p53, p21, cyclin D1, and membranous staining for HER2/neu oncoprotein, and both nuclear and cytoplasmic staining were scored for calgranulin and psoriasin. HER2/neu immunostain was scored from 0 to $3+$ as per the HerceptTest scoring method. In equivocal cases, HER2/neu gene amplification was determined by chromogenic in situ hybridisation (CISH). This was performed using the Zymed SPoT-Light HER2 CISH Polymer Detection kit (84-0146; Zymed, San Francisco, CA, USA). HER2/neu gene amplification was determined when there were six or more signals per nucleus or when clusters were identified in the cell nuclei. For ER and PR, a $10 \%$ cutoff value was used to categorise cases into positive or negative. The results of the other immunohistochemical markers were recorded as continuous variables, based on the proportion of 
positive tumour cells $(0-100 \%)$ regardless of staining intensity. The molecular markers psoriasin, calgranulin, p21, p53 and Ki67 do not have known cut points. Therefore, in addition to evaluating these markers as continuous variables, we compared the outcomes of cases with low immunostaining $(<10 \%)$ to those with higher staining $(\geqslant 10 \%)$. One pathologist $(\mathrm{SNM})$ evaluated all the immunostains. A second breast pathologist (WH) reviewed a sample of $20 \%$ of all the slides, as well as all slides where HER $2 /$ neu status was considered equivocal. The agreement between pathologists was greater than $90 \%$. The pathologists were blinded to the patient outcomes. All treatments and outcomes were confirmed by review of pathology and/or operative reports.

\section{Statistical analysis}

We performed a descriptive analysis to compare, for each of the nine markers, the proportion of patients who did and who did not recur. The differences in proportions for categorical variables were evaluated for significance using the $\chi^{2}$-test. Differences in means for continuous variables were evaluated for significance using Student's $t$-tests. We performed univariate and multivariate survival analyses using the Cox proportional hazards model to evaluate the associations between independent variables and the following outcomes: (1) any recurrence (local or invasive), (2) DCIS recurrence and (3) invasive recurrence. Local recurrence was defined as invasive cancer or DCIS that occurred in the ipsilateral breast, at least 6 months following the diagnosis of DCIS. We evaluated the association between the histological features of DCIS (tumour size, nuclear grade, the presence of multifocality, margin size and architectural subtype) and the outcomes. Tumour size was coded as the largest focus of DCIS $(\mathrm{cm})$. Nuclear grade and the presence of comedo necrosis were not entered into the model simultaneously because they were highly correlated. Analyses were adjusted for the effect of age at diagnosis and radiation. The administration of radiation was the strongest predictor of recurrence and there were no significant interactions observed between radiation and histopathological features of DCIS for any of the outcomes. Therefore, we repeated the analyses and present hazard ratios in women treated by breast-conserving surgery alone.

We then conducted the analyses to evaluate the relationship between molecular biomarker expression and the outcomes. We calculated multivariable hazards ratios and their corresponding 95\% confidence intervals (CI) initially for each marker alone and then for combinations of biomarkers. All multivariable analyses were adjusted for the effects of age at diagnosis and radiation. We also adjusted for the effect of nuclear grade because of reports that high grade DCIS may be more likely to over express HER2/neu (Latta et al, 2002). We calculated hazard ratios for psoriasin, calgranulin, Ki67, p53, cyclin D1 and p21 as continuous variables (to represent a change in the risk of recurrence per $10 \%$ change in cellular staining) and categorical variables, where positive represents $\geqslant 10 \%$ cells stain positive. There was no difference in the results; therefore, categorical results are presented. Hazard ratios for HER2/neu, ER status and PR status represent a change in the risk for positive compared with the negative status. Patients were followed from the date of diagnosis until either the date of recurrence, death from another cause, loss to follow-up or the date of the last clinic visit (or physician report). No patient withdrew from the study. Research ethics board approval was obtained.

\section{RESULTS}

\section{Cohort characteristics and outcomes}

We reviewed the medical records of 213 patients with DCIS. Among the 72 women treated with breast-conserving surgery and radiotherapy, there were eight recurrences (11\%) (five DCIS and three invasive). Median time of follow-up was 7.7 years (range $0.32,14.1$ years). The actuarial rate of local recurrence was $5.9 \%$ at 5 years and was $17.6 \%$ at 10 years. The rate of DCIS local recurrence was $4.5 \%$ at 5 years and was $10.8 \%$ at 10 years. The rate of invasive local recurrence was $1.4 \%$ at 5 years and was $7.7 \%$ at 10 years. Among women who experienced a recurrence, the median time to recurrence was 4.1 years for any recurrence, 2.5 years for DCIS recurrence and was 5.7 years for invasive local recurrence.

Of the 141 patients treated with breast-conserving surgery alone, there were 42 recurrences $(26 \%)$ including 3 distant recurrences. In all, 21 of the 42 local recurrences were invasive $(50 \%)$. The characteristics of these patients are presented in Tables 1 and 2 . The median time of follow-up for individuals treated by breastconserving surgery alone was 8.7 years (range $0-16.2$ years). The actuarial rate of local recurrence was $20 \%$ at 5 years and was $36 \%$ at 10 years. The rate of DCIS local recurrence was $14 \%$ at 5 years and was $18 \%$ at 10 years. The rate of invasive local recurrence was $7 \%$ at 5 years and was $22 \%$ at 10 years. Among women who experienced a recurrence, the median time to recurrence was 4.2 years for any recurrence, 2.6 years for DCIS recurrence and was 5.6 years for invasive local recurrence. Women treated by breastconserving surgery alone were slightly older at diagnosis, had smaller lesions and less likely to have high grade DCIS than women treated by breast-conserving surgery and radiation (Table 1).

\section{Predictors of local recurrence}

We performed univariable and multivariable analyses to evaluate the association between the histological features of DCIS and the development of any local recurrence, DCIS recurrence and invasive recurrence in women treated by BCS alone. The presence of high nuclear grade and multifocality were significantly associated with the development of any local recurrence. For high nuclear grade, the hazard ratio was 2.21 (95\% CI: 1.14, 4.29, $P=0.02$ ) for any local recurrence and was 4.09 (95\% CI: $1.49,11.23, P=0.01)$ for DCIS recurrence. For multifocality, the hazard ratio was 2.09 (95\% CI: $1.09,4.01, P=0.03)$ for any local recurrence and was 2.66 , (95\% CI: $1.03,6.88, P=0.04$ ) for DCIS local recurrence. None of the histological features of DCIS predicted for the development of invasive recurrence (Table 2).

Table 2 Histological predictors of local recurrence following breastconserving surgery alone for DCIS: multivariable analysis (adjusted for age at diagnosis)

\begin{tabular}{llc}
\hline Outcome & HR (95\% CI) & P-value \\
\hline Any local recurrence & & \\
$\quad$ High nuclear grade & $2.21(1.14,4.29)$ & 0.02 \\
Multifocality & $2.09(1.09,4.01)$ & 0.03 \\
Tumour size & $1.01(0.94,1.07)$ & 0.89 \\
Margin size & $0.96(0.86,1.06)$ & 0.40 \\
Architectural subtype (solid vs other) & $0.92(0.45,1.86)$ & 0.82 \\
& & \\
DCIS recurrence & & \\
High nuclear grade & $4.09(1.49,11.23)$ & 0.01 \\
Multifocality & $2.66(1.03,6.88)$ & 0.04 \\
Tumour size & $1.04(0.95,1.13)$ & 0.42 \\
Margin size & $1.01(0.87,1.16)$ & 0.95 \\
Architectural subtype (solid vs other) & $1.35(0.45,4.03)$ & 0.59 \\
& & \\
Invasive recurrence & & \\
$\quad$ High nuclear grade & $1.27(0.49,3.32)$ & 0.62 \\
Multifocality & $1.66(0.66,4.17)$ & 0.28 \\
$\quad$ Tumour size & $0.97(0.88,1.07)$ & 0.54 \\
Margin size & $0.92(0.79,1.07)$ & 0.28 \\
Architectural subtype (solid vs other) & $0.66(0.26,1.72)$ & 0.40 \\
\hline
\end{tabular}


Table 3 Molecular predictors of any local recurrence

\begin{tabular}{|c|c|c|c|c|}
\hline Variables & $\mathbf{N}$ & $\begin{array}{l}\text { No } \\
\text { of LR }\end{array}$ & $\begin{array}{c}\text { Hazard } \\
\text { ratio } \\
(95 \% \mathrm{CI})\end{array}$ & $P$-value \\
\hline \multicolumn{5}{|l|}{ Univariable analysis } \\
\hline HER2/neu+ & & & $2.11(1.21,3.68)$ & 0.01 \\
\hline Psoriasin $(\geqslant 10 \%)$ & & & $0.81(0.38,1.72)$ & 0.58 \\
\hline Calgranulin & & & $1.35(0.72,2.54)$ & 0.35 \\
\hline Ki67 $(\geqslant 10 \%)$ & & & $0.91(0.51, \mid .61)$ & 0.75 \\
\hline$p 53+(\geqslant 10 \%)$ & & & $0.89(0.49,1.59)$ & 0.68 \\
\hline ER positive & & & $0.85(0.47, \quad 1.53)$ & 0.59 \\
\hline PR positive & & & $0.94(0.53,1.65)$ & 0.82 \\
\hline Cyclin DI & & & $1.00(0.99,1.01)$ & 0.74 \\
\hline$p 21+(\geqslant 10 \%)$ & & & $1.04(0.59,1.81)$ & 0.90 \\
\hline \multicolumn{5}{|l|}{$\begin{array}{l}\text { Multivariable analysis } \\
\text { (adjusted for age and XRT) }\end{array}$} \\
\hline Her $2 /$ neu positive (vs other) & 58 & 22 & $2.10(1.19,3.69)$ & 0.01 \\
\hline HER2/neu+/Ki67+ (vs other) & 51 & 16 & $2.15(1.20,3.83)$ & 0.01 \\
\hline HER2/neu+/Ki67- (vs other) & 7 & 2 & $1.22(0.29,5.06)$ & 0.79 \\
\hline HER $2 /$ neu+/p53+(vs other) & 35 & 8 & $1.29(0.64,2.62)$ & 0.48 \\
\hline Ki67+/p53+ (vs other) & 63 & 12 & $1.23(0.65,2.33)$ & 0.53 \\
\hline HER2/neu+/Ki67+/p53+ (vs other) & 31 & 8 & $1.50(0.73,3.07)$ & 0.27 \\
\hline ER-/HER2/neu+/Ki67+ (vs other) & 31 & 11 & $1.52(0.77,2.99)$ & 0.23 \\
\hline
\end{tabular}

We calculated hazard ratios associated with each of the molecular markers (adjusting for the effect of radiotherapy and age at diagnosis); first for any local recurrence (non-invasive or invasive) and then for DCIS recurrence and invasive recurrence. (Table 3). HER2/neu overexpression was the only molecular marker associated with an increased risk of any local recurrence on univariable analysis (HR: $2.11,95 \% \mathrm{CI}: 1.21,3.68, P=0.01$ ).

In a univariable analysis, Ki-67 did not predict for local recurrence. However, on multivariable analysis, individuals with HER2neu + /Ki-67 + DCIS had a high likelihood of developing local recurrence. The 10-year rate of local recurrence was $39 \%$ (20/51) among HER2/neu + /Ki-67 + cases of DCIS compared with $18.5 \%(30 / 162)$ for cases without this profile $(P=0.0024)$. The hazard ratio for any local recurrence was 2.15 (95\% CI: $1.20-3.83$, $P=0.01)$, compared to women with other profiles. On multivariable analysis, individuals with HER $2 /$ neu $+/ \mathrm{Ki}-67+$ profile were three times more likely to develop a non-invasive recurrence $(\mathrm{HR}=3.22,95 \% \mathrm{CI}: 1.47,7.03, P=0.003)$ compared with cases with other molecular phenotypes. The effect of the expression profile was independent of nuclear grade (Figure 1).

Although the rate of DCIS recurrence was higher for cases with HER2/neu + /Ki67 + DCIS (13/51 (26\%) compared with 13/162 $(8 \%)$ for cases without this profile, $P=0.0009$ ), we could not determine the effect of Ki67 positivity in the presence of HER2/neu positivity, because the majority $(51 / 58)$ of HER $2 /$ neu + cases were $\mathrm{Ki} 67+$. Among the seven cases with HER2/neu + /Ki-67- DCIS, none developed a DCIS recurrence and two developed an invasive recurrence. None of the molecular markers, either alone or in combination, were associated with an increased risk of invasive recurrence (Tables 4 and 5).

\section{DISCUSSION}

Our findings corroborate the results of a study by Kerlikowske et al (2010) of a population-based cohort of individuals with DCIS treated by breast-conserving surgery alone. In this earlier study, DCIS with HER2/neu + /Ki67 + expression was associated with a higher risk of DCIS recurrence (univariate $\mathrm{HR}=1.9,95 \% \mathrm{CI}$ : $1.0-3.5)$ but was not associated with the development of invasive recurrence. In the present study, the two-marker profile was also associated with a high risk of DCIS recurrence (multivariate
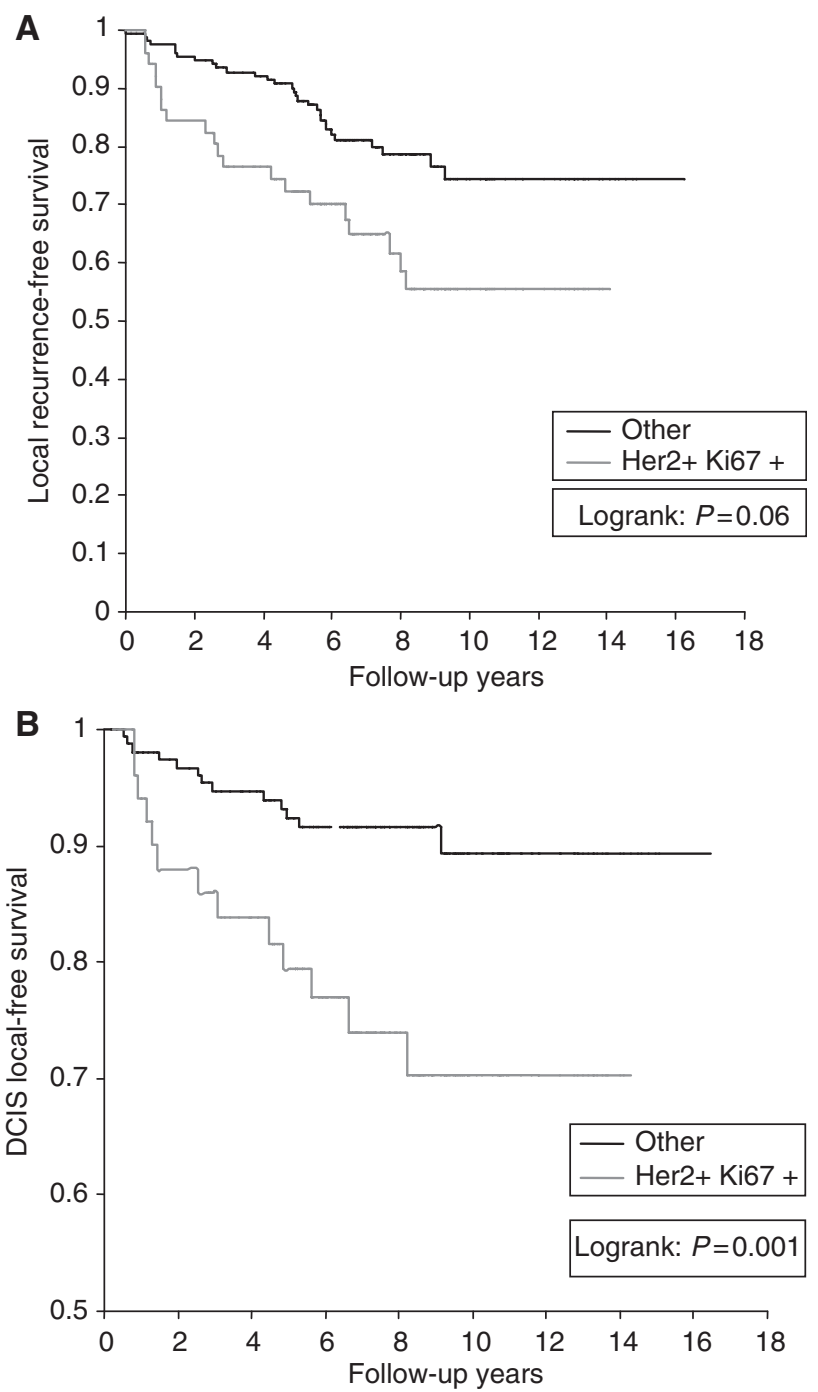

Figure I Her2/neu and Ki67 expression in DCIS is associated with the development of local recurrence $(\mathbf{A})$ and DCIS recurrence $(\mathbf{B})$.

$\mathrm{HR}=3.22,95 \% \mathrm{CI}: 1.47,7.03, P=0.003)$ and not with invasive recurrence.

The effect of HER2/neu/Ki67 positivity was independent of nuclear grade. In contrast to the Kerlikowske study, we did not find that the addition of ER status to the two-marker profile added additional predictive information. The differences between the two studies may be due to the differences in patient populations, the precision of the hazards ratio estimate or to differences in the coding of HER2/neu positivity. Both studies coded DCIS lesions with a score of $3+$ on immunostaining for HER2/neu as HER2/neu positive but DCIS lesions with equivocal immunostaining for HER2/neu (score of $2+$ ) were scored as positive in the Kerlikowske study. We performed in situ hybridisation on all equivocal cases and only lesions with amplification were coded as HER2/neu + .

We studied a total of nine molecular markers for their ability to predict the development of recurrence following treatment of DCIS with breast-conserving therapy in a large cohort with long-term follow-up interval. We systematically evaluated histopathological features of DCIS and molecular biomarkers associated with the development of any local recurrence, DCIS local recurrence or invasive local recurrence. None of the markers was predictive of invasive recurrence. 
Table 4 Molecular predictors of non-invasive (DCIS) local recurrence

\begin{tabular}{|c|c|c|c|c|}
\hline & $\mathbf{N}$ & $\begin{array}{c}\text { No of } \\
\text { DCIS } \\
\text { LR }\end{array}$ & $\begin{array}{c}\text { Hazard } \\
\text { ratio } \\
(95 \% \mathrm{Cl})\end{array}$ & $P$-value \\
\hline \multicolumn{5}{|l|}{ Univariable analysis } \\
\hline HER2/neu+ & & & $2.72(1.26,5.88)$ & 0.01 \\
\hline Psoriasin $(\geqslant 10 \%)$ & & & $1.30(0.52,3.24)$ & 0.57 \\
\hline Calgranulin $(\geqslant 10 \%)$ & & & $1.47(0.62,3.49)$ & 0.39 \\
\hline Ki67 $(\geqslant 10 \%)$ & & & $1.05(0.47,2.35)$ & 0.91 \\
\hline $\mathrm{p} 53(\geqslant 10 \%)$ & & & $0.89(0.40,1.99)$ & 0.77 \\
\hline ER positive & & & I.I $4(0.48,2.7 \mid)$ & 0.77 \\
\hline PR positive & & & $0.71(0.33,1.53)$ & 0.37 \\
\hline Cyclin DI ( $\geqslant 10 \%)$ & & & I.0I $(0.99,1.02)$ & 0.52 \\
\hline$p 21(\geqslant 10 \%)$ & & & $1.24(0.57,2.71)$ & 0.58 \\
\hline \multicolumn{5}{|l|}{$\begin{array}{l}\text { Multivariable analysis } \\
\text { (adjusted for age and XRT) }\end{array}$} \\
\hline Her2/neut & 58 & 13 & $2.67(1.23,5.79)$ & 0.01 \\
\hline HER2/neu+/Ki67+ (vs other) & 51 & 10 & $3.22(1.47,7.03)$ & 0.003 \\
\hline HER2/neu+/Ki67- (vs other) & 7 & 0 & Not calculable & \\
\hline HER2/neu+/p53+(vs other) & 35 & 5 & $1.54(0.61,3.91)$ & 0.36 \\
\hline Ki67+/p53+ (vs other) & 63 & 6 & $1.09(0.44,2.67)$ & 0.86 \\
\hline HER2/neu+/Ki67+/p53+ (vs other) & 31 & 5 & $1.79(0.70,4.57)$ & 0.22 \\
\hline ER-/HER2/neu+/Ki67+ (vs other) & 31 & 6 & $1.65(0.66,4.15)$ & 0.28 \\
\hline
\end{tabular}

Overall, a third (31\%) of women with HER $2 /$ neu $+/$ Ki67 + DCIS developed local recurrence following breast-conserving therapy compared to $16 \%(26 / 162)$ with different biomarker profiles. Among women who were not treated with radiotherapy, the risk associated with this profile was $47 \%$. Among 17 women with this profile, who were treated with breast-conserving surgery and radiation, $(24 \%)$ developed a local recurrence. This data suggests that women with HER2/neu $+/ \mathrm{Ki} 67+$ DCIS are not optimal candidates for the treatment by breast-conserving surgery alone. Further research in other large cohorts is needed to evaluate the long-term outcomes of women with HER2/neu $+/$ Ki67 + DCIS treated with BCS and radiation.

The identification of molecular predictors in DCIS is challenging because the number of recurrences is low and the expression levels of molecular biomarkers are often correlated (Latta et al, 2002). This limits our ability to evaluate multiple markers simultaneously in a multivariable model. Cut point values for many molecular markers have not been established. Furthermore, systematic pathological and molecular evaluation and long-term follow-up is required. As a result, most studies have been limited in statistical
Table 5 Molecular predictors of invasive recurrence

\begin{tabular}{|c|c|c|c|c|}
\hline Univariable analysis & $\mathbf{N}$ & $\begin{array}{c}\text { No } \\
\text { of Inv } \\
\text { LR }\end{array}$ & $\begin{array}{c}\text { Hazard } \\
\text { ratio } \\
(95 \% \mathrm{Cl})\end{array}$ & $P$-value \\
\hline HER2/neu+ & & & $1.58(0.69,3.62)$ & 0.28 \\
\hline Psoriasin $(\geqslant 10 \%)$ & & & $0.38(0.09,1.60)$ & 0.19 \\
\hline Calgranulin $(\geqslant 10 \%)$ & & & $1.24(0.49,3.12)$ & 0.65 \\
\hline Ki67 ( $\geqslant 10 \%)$ & & & $0.79(0.35,1.77)$ & 0.56 \\
\hline $\mathrm{p} 53(\geqslant 10 \%)$ & & & $0.88(0.38,2.06)$ & 0.77 \\
\hline ER positive & & & $0.64(0.29,1.45)$ & 0.29 \\
\hline PR positive & & & $1.30(0.55,3.03)$ & 0.55 \\
\hline Cyclin DI $(\geqslant 10 \%)$ & & & $0.99(0.98,1.01)$ & 0.85 \\
\hline$p 21(\geqslant 10 \%)$ & & & $0.85(0.38,1.90)$ & 0.69 \\
\hline \multicolumn{5}{|l|}{$\begin{array}{l}\text { Multivariable analysis } \\
\text { (adjusted for age and XRT) }\end{array}$} \\
\hline HER2/neu/neu+ & 58 & 9 & $1.61(0.70,3.73)$ & 0.26 \\
\hline HER2/neu+/Ki67+ (vs other) & 51 & 6 & $1.33(0.54,3.28)$ & 0.54 \\
\hline HER2/neu+/Ki67- (vs other) & 7 & 2 & $1.22(0.29,5.06)$ & 0.79 \\
\hline HER2/neu+/p53+(vs other) & 35 & 3 & $1.04(0.35,3.11)$ & 0.94 \\
\hline Ki67+/p53+ (vs other) & 63 & 6 & $1.41(0.57,3.52)$ & 0.46 \\
\hline HER2/neu+/Ki67+/p53+ (vs other) & 31 & 3 & $1.22(0.40,3.69)$ & 0.73 \\
\hline ER-/HER2/neu+/Ki67+ (vs other) & 31 & 5 & $1.39(0.51,3.78)$ & 0.52 \\
\hline
\end{tabular}

power and have not differentiated biomarker profiles associated with invasive recurrences and non-invasive recurrences (Ringberg et al, 2001; Provenzano et al, 2003; Cornfield et al, 2004). However, as we show here, the molecular alterations associated with DCIS local recurrence differ from those associated with invasive recurrence. It is important to distinguish these two endpoints. Further research is needed to identify biomarkers that distinguish individuals at risk of DCIS recurrence from those at risk of developing invasive recurrence, to further evaluate the effect of joint expression of HER2/neu and Ki67 and of other combinations of biomarkers on the risks of local and invasive recurrence and to evaluate the effect of radiation on these outcomes.

\section{ACKNOWLEDGEMENTS}

This work was funded by a grant from the Canadian Breast Cancer Research Alliance. We would like to thank Ms Barb Zurowski for assistance with the manuscript preparation.

\section{REFERENCES}

Cornfield DB, Palazzo JP, Schwartz GF, Goonewardene SA, Kovatich AJ, Chervoneva I, Hyslop T, Schwarting R, Cornfield DB, Palazzo JP, Schwartz GF, Goonewardene SA, Kovatich AJ, Chervoneva I, Hyslop T, Schwarting R (2004) The prognostic significance of multiple morphologic features and biologic markers in ductal carcinoma in situ of the breast: a study of a large cohort of patients treated with surgery alone. Cancer 100: 2317-2327

Edge SB, Byrd DR, Compton CC, Fritz AG, Greene FL, Trotti A (eds) (2010) AJCC cancer staging manual, 7th edn. Springer: New York, NY

Ernster VL, Ballard-Barbash R, Barlow WE, Zheng Y, Weaver DL, Cutter G, Yankaskas BC, Rosenberg R, Carney PA, Kerlikowske K, Taplin SH, Urban N, Geller BM (2002) Detection of ductal carcinoma in situ in women undergoing screening mammography. JNCI Cancer Spectrum 94: 1546-1554

Fisher B, Dignam J, Wolmark N, Mamounas E, Costantino J, Poller W, Fisher ER, Wickerham DL, Deutsch M, Margolese R, Dimitrov N, Kavanah M (1998) Lumpectomy and radiation therapy for the treatment of intraductal breast cancer: findings from National Surgical Adjuvant Breast and Bowel Project B-17. J Clin Oncol 16: 441-452
Holland R, Peterse JL, Millis RR, Eusebi V, Faverly D, van de Vijver MJ, Zafrani B (1994) Ductal carcinoma in situ: a proposal for a new classification. Semin Diagn Pathol 11: 167-180

Houghton J, George WD, Cuzick J, Duggan C, Fentiman IS, Spittle M, UK Coordinating Committee on Cancer Research, Ductal Carcinoma in situ Working Party, DCIS trialists in the UK AaNZ (2003) Radiotherapy and tamoxifen in women with completely excised ductal carcinoma in situ of the breast in the UK, Australia, and New Zealand: randomised controlled trial. Lancet 362: 95-102

Julien JP, Bijker N, Fentiman IS, Peterse JL, Delledonne V, Rouanet P, Avril A, Sylvester R, Mignolet F, Bartelink H, van Dongen JA (2000) Radiotherapy in breast-conserving treatment for ductal carcinoma in situ: first results of the EORTC randomised phase III trial 10853. EORTC Breast Cancer Cooperative Group and EORTC Radiotherapy Group. Lancet 355: 528-533

Kerlikowske K, Molinaro AM, Gauthier ML, Berman HK, Waldman F, Bennington J, Sanchez H, Jimenez C, Stewart K, Chew K, Ljung BM, Tlsty TD (2010) Biomarker expression and risk of subsequent tumors 
after initial ductal carcinoma in situ diagnosis. J Natl Cancer Inst 102: $627-637$

Latta EK, Tjan S, Parkes RK, O'Malley FP, Latta EK, Tjan S, Parkes RK, O'Malley FP (2002) The role of HER2/neu overexpression/amplification in the progression of ductal carcinoma in situ to invasive carcinoma of the breast. Mod Pathol 15: 1318-1325

Lauzier S, Levesque P, Drolet M, Coyle D, Brisson J, Masse B, Robidoux A, Robert J, Maunsell E (2011) Out-of-pocket costs for accessing adjuvant radiotherapy among Canadian women with breast cancer. J Clin Oncol 29: $4007-4013$

Paszat LF, Mackillop WJ, Groome PA, Boyd C, Schulze K, Holowaty E (1998) Mortality from myocardial infarction after adjuvant radiotherapy for breast cancer in the surveillance, epidemiology, and end-results cancer registries. J Clin Oncol 16: 2625-2631, (published erratum appears in Feb $1999 \mathrm{~J}$ Clin Oncol; 17(2): 740)

Paszat LF, Vallis KA, Benk VM, Groome PA, Mackillop WJ, Wielgosz A (2007) A population-based case-cohort study of the risk of myocardial infarction following radiation therapy for breast cancer. Radiother Oncol 82: 294-300 Provenzano E, Hopper JL, Giles GG, Marr G, Venter DJ, Armes JE, Provenzano E, Hopper JL, Giles GG, Marr G, Venter DJ, Armes JE (2003) Biological markers that predict clinical recurrence in ductal carcinoma in situ of the breast. Eur J Cancer 39: 622-630
Ringberg A, Anagnostaki L, Anderson H, Idvall I, Ferno M, Ringberg A, Anagnostaki L, Anderson H, Idvall I, Ferno M, South Sweden Breast Cancer Group (2001) Cell biological factors in ductal carcinoma in situ (DCIS) of the breast-relationship to ipsilateral local recurrence and histopathological characteristics. Eur J Cancer 37: $1514-1522$

Seth A, Kitching R, Landberg G, Xu J, Zubovits J, Burger AM (2003) Gene expression profiling of ductal carcinomas in situ and invasive breast tumors. Anticancer Res 23: 2043-2051

Sikand K, Lee AH, Pinder SE, Elston CW, Ellis IO, Sikand K, Lee AHS, Pinder SE, Elston CW, Ellis IO (2005) Sections of the nipple and quadrants in mastectomy specimens for carcinoma are of limited value. J Clin Pathol 58: 543-545

Silverstein MJ, Lagios MD, Martino S, Lewinsky BS, Craig PH, Beron PJ, Gamagami P, Waisman JR (1998) Outcome after invasive local recurrence in patients with ductal carcinoma in situ of the breast. J Clin Oncol 16: $1367-1373$

Solin LJ, Fourquet A, McCormick B, Haffty B, Recht A, Schultz DJ, Barrett W, Fowble BL, Kuske R, Taylor M (1994) Salvage treatment for local recurrence following breast-conserving surgery and definitive irradiation for ductal carcinoma in situ (intraductal carcinoma) of the breast. Int J Radiat Oncol Biol Phys 30: 3-9

This work is published under the standard license to publish agreement. After 12 months the work will become freely available and the license terms will switch to a Creative Commons Attribution-NonCommercial-Share Alike 3.0 Unported License. 